\title{
Estimation of Compositions of Zr-Cu Binary Sputtered Film and Its Characterization
}

\author{
Katsuyoshi Kondoh, ${ }^{1}$ Junji Fujita, ${ }^{2}$ Junko Umeda, ${ }^{1}$ and Tadashi Serikawa ${ }^{1}$ \\ ${ }^{1}$ Joining and Welding Research Institute, Osaka University, 11-1 Mihogaoka, Ibaragi, Osaka 567-0047, Japan \\ ${ }^{2}$ Department of Mechanical Engineering, Osaka University, 1-1 Yamadaoka, Suita, Osaka 565-0871, Japan
}

Correspondence should be addressed to Katsuyoshi Kondoh, kondoh@jwri.osaka-u.ac.jp

Received 28 August 2008; Accepted 26 November 2008

Recommended by Yiu-Wing Mai

$\mathrm{Zr}-\mathrm{Cu}$ amorphous films were prepared by radio-frequency (RF) magnetron sputtering on glass substrate using two kinds of the elemental composite targets: $\mathrm{Cu}$ chips on $\mathrm{Zr}$ plate and $\mathrm{Zr}$ chips on $\mathrm{Cu}$ plate. It was easy to precisely control chemical compositions of sputtered films by selecting the chip metal and the number of chips. It is possible to accurately estimate the film compositions by using the sputtered area and the deposition rate of $\mathrm{Cu}$ and $\mathrm{Zr}$. XRD analysis on every as-sputtered film showed the broadened pattern. Zr-rich composition film, however, revealed a small peak at the diffraction angle of $2 \theta=35^{\circ}$, and Cu-rich one indicated it at $2 \theta=43^{\circ}$. TEM and electron diffraction analysis on the former also showed the main $\mathrm{Zr}$ ring patterns and its streaks. Zr-rich composition film with $\mathrm{Cu}$ content of 34 at $\%$ or less indicated a good corrosion resistance by salt spray test. On the other hand, $\mathrm{Cu}$-rich version with 74 at $\% \mathrm{Cu}$ or more was poor in corrosion resistance. This was because $\mathrm{Zr}$ was reactively passive, and caused the spontaneous formation of a hard non-reactive surface film that inhibited further corrosion than $\mathrm{Cu}$.

Copyright (๑) 2008 Katsuyoshi Kondoh et al. This is an open access article distributed under the Creative Commons Attribution License, which permits unrestricted use, distribution, and reproduction in any medium, provided the original work is properly cited.

\section{Introduction}

A sputtering process is useful to form the amorphousstructured films to be widely used as high-performance materials such as oxide and metallic films in the industrial fields [1-3]. Characteristics of the films strongly depend on their compositions and structures controlled by both sputtering conditions and compositions of target materials [4-6]. In particular, $\mathrm{Zr}-\mathrm{Cu}$ alloys are well known as metallic glass materials $[7,8]$, having an obvious glass-liquid transition temperature $(\mathrm{Tg})$, high strength and toughness. Bulk metallic glass (BMG) shows a high corrosion resistance due to the absence of grain boundaries [9]. Thus, a metallic glass film is a promising candidate for suitable surface treatments to improve the corrosion resistance of poor resistance light metals, such as aluminum, titanium, and magnesium alloys [10-12]. In this study, RF magnetron sputtering process was applied to form $\mathrm{Zr}-\mathrm{Cu}$ amorphous films with various compositions because of its advantages of the low-temperature deposition and high controllability in the deposition $[13,14]$. The compositions of sputtered films were estimated by using the deposition rate and sputtered area of each metal in the composite target. The structure of the films was analyzed by XRD, and the crystallization behavior in annealing was evaluated by XRD and TEM observation. The corrosion resistance of $\mathrm{Zr}-\mathrm{Cu}$ thin films was also investigated in the conventional salt spray test.

\section{Experimental}

$\mathrm{Zr}-\mathrm{Cu}$ binary films were deposited by a $13.56 \mathrm{MHz}$ radiofrequency (RF) planer-magnetron sputtering. The elementally composed targets of $\mathrm{Zr}$ and $\mathrm{Cu}$ chips and plates were used in this study. For example, a composite target having 4 pieces $\mathrm{Cu}$ chips on $\mathrm{Zr}$ disk plate was shown in Figure 1 . Films were deposited on glass substrates placed on the watercooled substrate holder in the sputtering chamber evacuated to $1.0 \times 10^{-4} \mathrm{~Pa}$ pressure. A high-purity (99.999\%) argon gas was used as a sputtering gas in $101.33 \mathrm{~Pa}$. The chemical compositions of sputtered films were controlled by changing the number of chips. Before starting the film deposition, the presputtering was carried out by placing a shutter-plate 


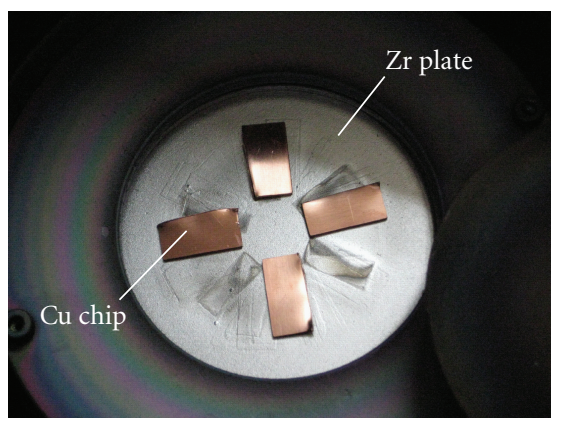

Figure 1: Photograph of elemental composite target used in this study ( $\mathrm{Cu}$ chips on Zr disk plate).

between the target and substrate to remove the contaminated surface layer of the target. Sputtering power and sputtering gas pressure were fixed at 150 watts and $1.33 \mathrm{~Pa}$, respectively. The thickness of the films was about $1 \mu \mathrm{m}$ by 900 seconds sputtering. The annealing condition was $723 \mathrm{~K}$ for 900 seconds in Ar gas atmosphere. X-ray Diffraction (XRD) analysis with $\mathrm{K}-\alpha$ and transmission electron microscope (TEM) measurements were carried out on each sputtered film to investigate the crystallization behavior by annealing. The salt spray test (SST) according to Japan Industrial Standard (JIS) Z 2731 [15] was carried out for 96 hours to evaluate the corrosion resistance.

\section{Results and Discussion}

$\mathrm{Zr}-\mathrm{Cu}$ amorphous thin films with various compositions are deposited by changing the number of $\mathrm{Zr}$ or $\mathrm{Cu}$ chips on another metal plate. Figure 2(a) shows XRD patterns of the sputtered films, and $\mathrm{Cu}$ content for each one was quantitatively measured by electron probe micro-analysis (EPMA). Basically, each shows a broadened pattern meaning an amorphous structure, that is, $\mathrm{Zr}-\mathrm{Cu}$ binary sputtered films are completely amorphous in the wide range of $\mathrm{Cu}$ compositions. In the case of the $\mathrm{Cu}$ content with 34 at $\%$ or less, however, such Zr-rich films indicate a small peak at $2 \theta=$ $35^{\circ}$, corresponding to a crystallized zirconium as mentioned below. The Cu-rich films with 84 at $\% \mathrm{Cu}$ or more clearly reveal a diffraction peak at $2 \theta=43^{\circ}$. After annealing each film at $723 \mathrm{~K}$ for 900 seconds in Ag gas atmosphere, as shown in Figure 2(b), XRD patterns in $\mathrm{Zr}$ or $\mathrm{Cu}$ rich composition films reveal remarkably crystalline $\mathrm{Zr}$ and $\mathrm{Cu}$ peaks at $2 \theta=35^{\circ}$ and $43^{\circ}$, respectively. Zr peak intensity gradually increases with increase in $\mathrm{Zr}$ content of the film. Figure 3(a) shows TEM observation of as-sputtered $\mathrm{Zr}-\mathrm{Cu}$ film with 34 at $\% \mathrm{Cu}$ and its electron diffraction pattern. It basically consists of an amorphous structure. Some spots, however, indicating a crystalline $\mathrm{Zr}$, are detected in electron diffraction pattern. It corresponds to a small $\mathrm{Zr}$ peak at $2 \theta=35^{\circ}$ in Figure 2(a). As shown in Figure 3(b), the $\mathrm{Zr}-\mathrm{Cu}$ sputtered film with $34 \mathrm{at} \% \mathrm{Cu}$ annealed at $723 \mathrm{~K}$ in $\mathrm{Ar}$ gas consists of fine $\mathrm{Zr}$ crystal grains with $20 \sim 40 \mathrm{~nm}$. Accordingly, two kinds of small peaks at $2 \theta=35^{\circ}$ and $43^{\circ}$ of as-sputtered films in Figure 2(a) correspond to the nucleation sites of crystalline $\mathrm{Zr}$ and $\mathrm{Cu}$, respectively. They are completely crystallized by annealing at elevated temperature.

The estimation of $\mathrm{Zr}-\mathrm{Cu}$ film compositions was carried out when changing the number of each chip, and compared to those measured by EPMA. In this study, it is supposed that there is no effect of the contacts between $\mathrm{Zr}$ and $\mathrm{Cu}$ atoms on each deposition rate in sputtering when employing the elemental composite $\mathrm{Zr}$-Cu target. That is, the composition of $\mathrm{Zr}$-Cu films is determined by both the deposition rate and the sputtered area in using the single-metal target. The EPMA result indicates that $\mathrm{Cu}$ composition ratio of each sputtered film is in proportional to the number of chips when using both of $\mathrm{Zr}$ and $\mathrm{Cu}$ chips. That is, it is possible to control the sputtered film composition by selecting the metal chip and its number of pieces. Concerning the estimation of the film compositions by using the deposition rate, for example, $\mathrm{Cu}$ content of the film $\left(\gamma_{\mathrm{Cu}}\right)$ is simply expressed by the sputtered area and deposition rate as shown in (1)

$$
\gamma_{\mathrm{Cu}}=\frac{\eta_{\mathrm{Cu}} S_{\mathrm{Cu}}}{\left(\eta_{\mathrm{Cu}} S_{\mathrm{Cu}}+\eta_{\mathrm{Zr}} S_{\mathrm{Zr}}\right)},
$$

where $\eta$ is a deposition rate and $S$ is sputtered area.

When considering that the density of the sputtered film is constant, the following equation is obtained

$$
M \times y=\rho \times t \times 10^{-18},
$$

where $t$; film thickness $(\mu \mathrm{m}), M$; atomic mass, $y$; amount of substance per unit area (mol).

In (2), $y$ value of each metal corresponds to each deposition rate $(\eta)$, and estimated by measuring the film thickness $(t)$ in using each metal target. In this experiment, $y_{\mathrm{Cu}}=3.05 \times 10^{-13} \mathrm{~mol}$ and $y_{\mathrm{Zr}}=0.60 \times 10^{-13} \mathrm{~mol}$ are obtained when the thickness of the $\mathrm{Cu}$ film and $\mathrm{Zr}$ one are $0.8335 \mu \mathrm{m}$ and $2.1767 \mu \mathrm{m}$, respectively. Then, the ration of each deposition rate $\left(\alpha=\eta_{\mathrm{Cu}} / \eta_{\mathrm{Zr}}\right)$ is 5.081 . Furthermore, by using this $\alpha$ value, $\mathrm{Cu}$ content of the film is calculated by the following (3):

$$
\gamma_{\mathrm{Cu}}=\frac{\alpha \beta}{(1-\beta+\alpha \beta)}, \quad \beta=\frac{S_{\mathrm{Cu}}}{\left(S_{\mathrm{Cu}}+S_{\mathrm{Zr}}\right)} .
$$

Figure 4 indicates a relationship between $\mathrm{Cu}$ composition ratio by EPMA and $\mathrm{Cu}$ sputtered area ratio $(\beta)$. When using the composite targets which consist of $\mathrm{Zr}$ chips and $\mathrm{Cu}$ plate, EPMA measurement corresponds to the calculated values with $\alpha=4$.

The previous study reported that $\alpha$ was $3.9 \sim 4.0$ when using argon ion sputtering with a reflection ion energy of $100 \sim 300 \mathrm{eV}$. Accordingly, the estimation of the film compositions by (3) is significantly accurate. On the other hand, in the case of the target consisting of $\mathrm{Cu}$ chips and $\mathrm{Zr}$ plate, the measured $\mathrm{Cu}$ content is smaller than that of calculated values with $\alpha=4$. This is because of the gradual decrease of $\mathrm{Cu}$ intensity ( $\circ$ ) with increase in the sputtering time as shown in Figure 5. The brown color of as-received $\mathrm{Cu}$ chip surface changed into dark brown after discharging in 2.4 kiloseconds. The $\mathrm{Cu}$ intensity, however, shows a stably constant value $(\square)$ in using $\mathrm{Zr}$ chips on the $\mathrm{Cu}$ plate. EPMA 


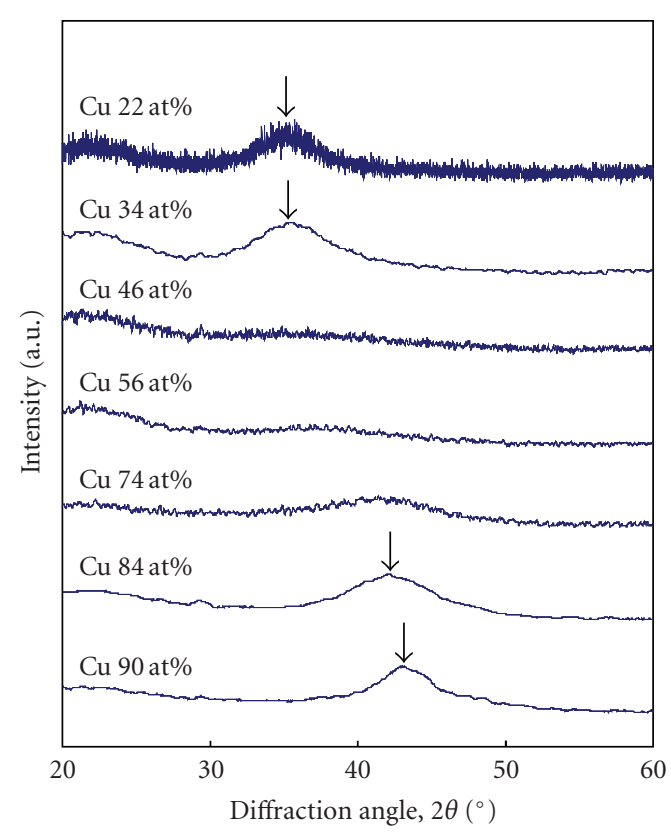

(a)

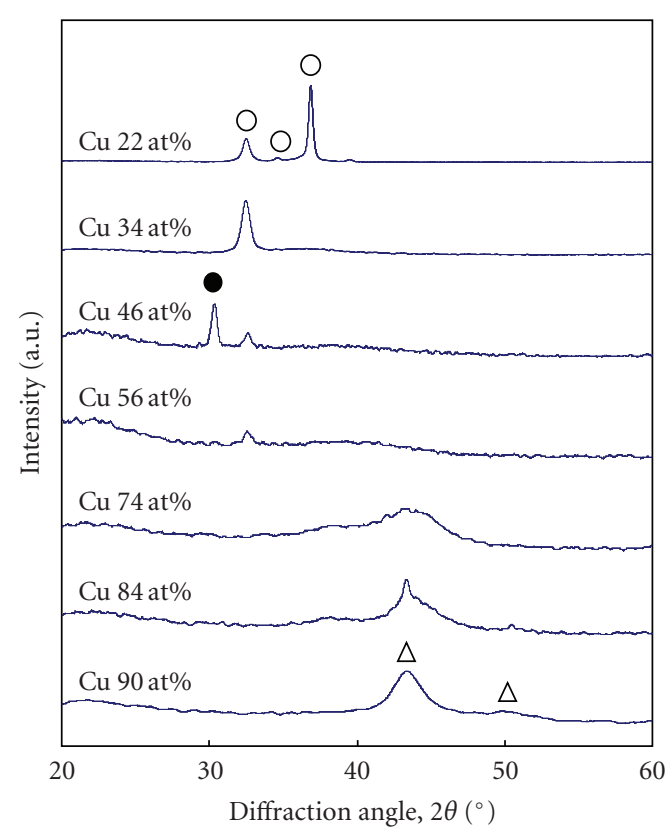

$\mathrm{Zr}$
$\mathrm{ZrO}_{2}$
$\triangle \mathrm{Cu}$
(b)

Figure 2: X-ray diffraction patterns of $\mathrm{Zn}$-Cu binary sputtered films with various Cu contents; (a) as-sputtered films and (b) after annealed at $723 \mathrm{~K}$ for 900 seconds in argon gas atmosphere.

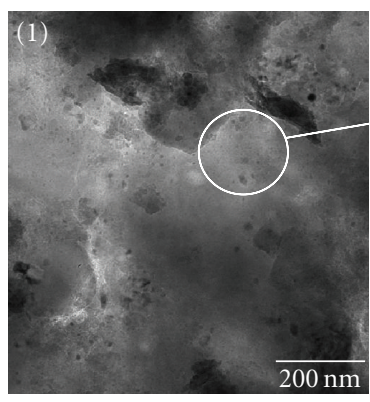

(a)

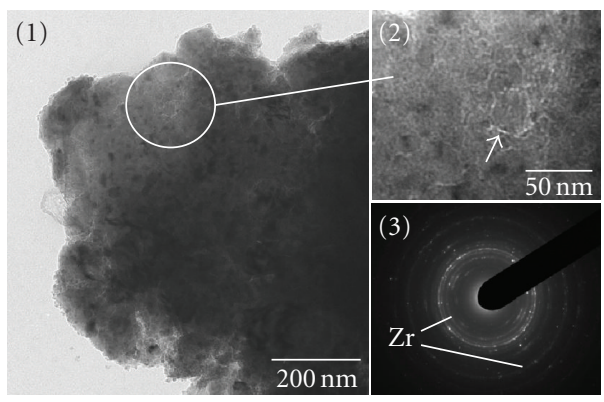

(b)

Figure 3: (a) TEM observation of as-sputtered $\mathrm{Zr}-\mathrm{Cu}$ film with $34 \mathrm{at} \% \mathrm{Cu}$, and (b) annealed at $723 \mathrm{~K}$ in argon gas atmosphere.

on the dark brown $\mathrm{Cu}$ chip specimen indicated that $\mathrm{Zr}$ fine particles originated in the target plate covered the chip surface, and caused the reduction of $\mathrm{Cu}$ deposition rate in sputtering.

Figure 6 shows the salt spray test results of as-sputtered films with various $\mathrm{Cu}$ contents on the silica glass plate. The specimens with $\mathrm{Cu}$ content of 34 at $\%$ or less indicates a good corrosion resistance even after continuously spraying for 96 hours. The conventional 316 stainless steel, which is one of the standard corrosion resistant materials, also shows no damage after 96 hours SST under the same conditions. In the case of 56 at $\% \mathrm{Cu}$ content, the sputtered film reveals locally damaged area around the glass plate. It means the corrosion is due to the poor bonding between the film and glass plate. The Zr-rich films with crystallized Zr peaks annealed at $723 \mathrm{~K}$ also show no corrosion damage after SST for 96 hours. In considering the standard electrode potential of $\mathrm{Zr}(-1.539 \mathrm{~V})$ and $\mathrm{Cu}(+0.337 \mathrm{~V})$, the voltage $(1.876 \mathrm{~V})$ is effective to accelerate the galvanic corrosion in the crystallized film. However, as mentioned above, this film showed no corrosion damage. It is well known that $\mathrm{Zr}$ easily forms passive films in heating under oxidizing atmosphere [16]. In the SST on the crystallized Zr-rich film after annealing, the passivation due to zirconium oxides causes the control of the corrosion phenomenon. On the other hand, with increase in $\mathrm{Cu}$ content of the sputtered films, the poor passivation of $\mathrm{Cu}$ is not effective to obstruct corrosion damages in SST as shown in Figure 6. 


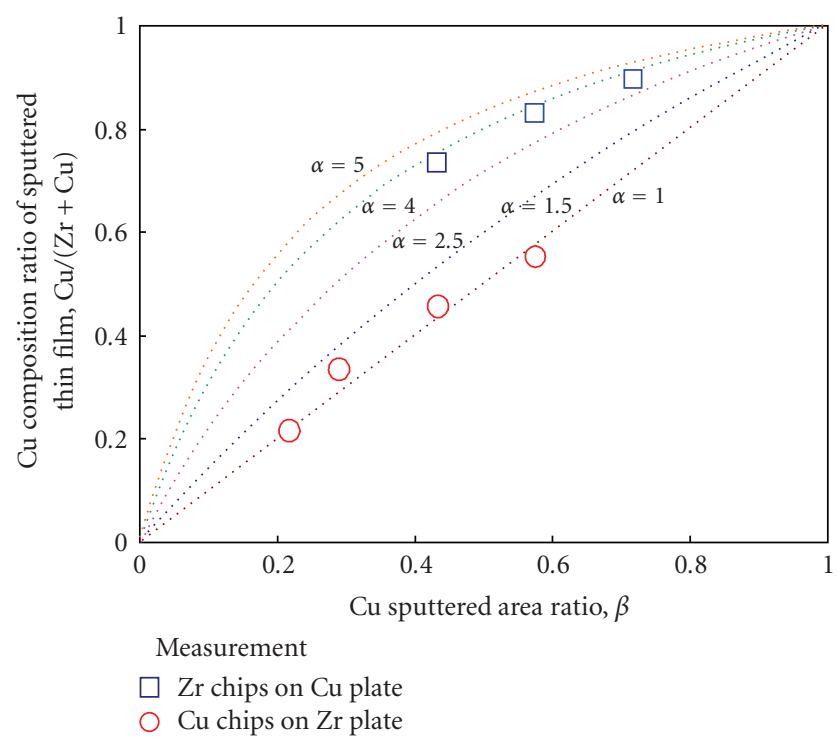

FIgURE 4: Relationship between $\mathrm{Cu}$ composition ratio of sputtered films and $\mathrm{Cu}$ sputtered area ratio of elemental composite targets.

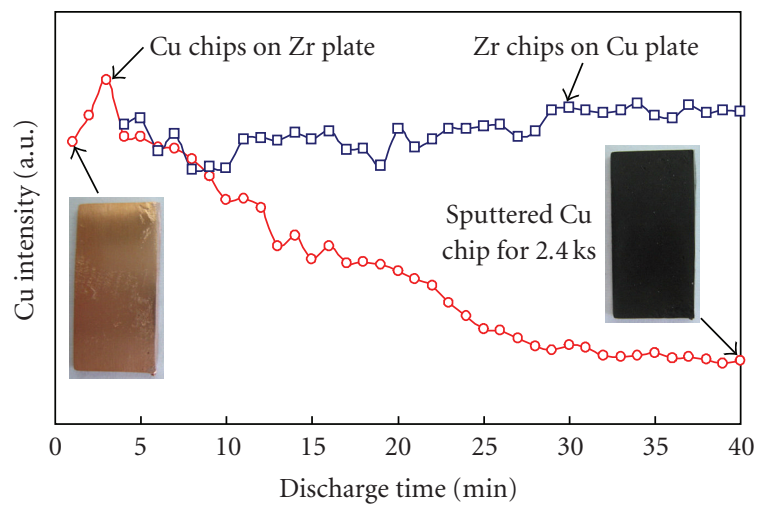

Figure 5: Changes of $\mathrm{Cu}$ intensity in spectral diffraction of $\mathrm{Cu}-\mathrm{Zr}$ sputtered films on discharge time in sputtering when using $\mathrm{Cu}$ chips on $\mathrm{Zr}$ plate and $\mathrm{Zr}$ chips on $\mathrm{Cu}$ plate composite targets.

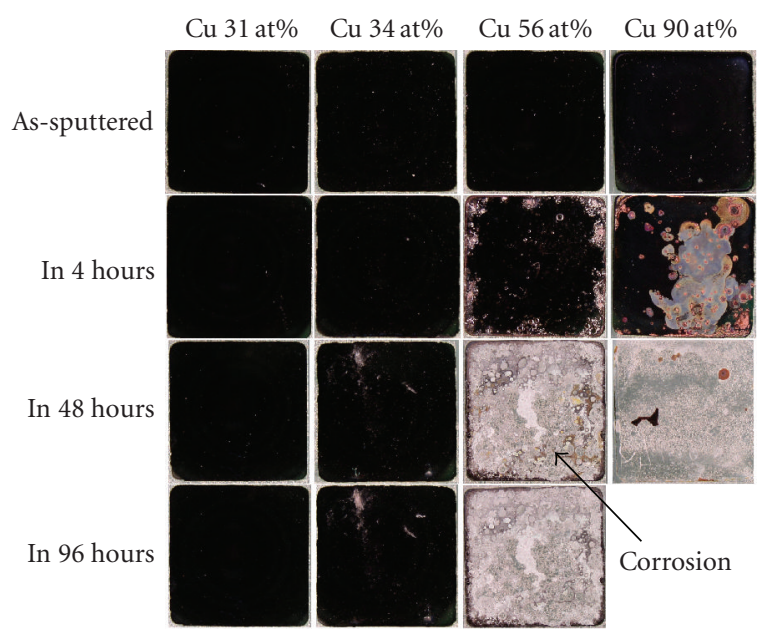

FIGURE 6: Salt spray test result of as-sputtered $\mathrm{Zr}$-Cu binary films in various spraying films.

\section{Conclusion}

The accurate estimation of the sputtered film compositions was carried out by calculating the deposition rate in sputtering and the sputtered area of each metal used in the composite target. In the case of $\mathrm{Cu}$ chips on $\mathrm{Zr}$ plate target, the measured $\mathrm{Cu}$ contents of the film was smaller than the calculated values because of the reduction of $\mathrm{Cu}$ deposition rate due to $\mathrm{Zr}$ fine particles covering the $\mathrm{Cu}$ chip surface. All as-sputtered films showed a broadened pattern in XRD analysis. After annealing at $723 \mathrm{~K}, \mathrm{Zr}$-rich composition film indicated a small peak of crystallized $\mathrm{Zr}$ at $2 \theta=35^{\circ}$. Zr-rich films with 34 at $\% \mathrm{Cu}$ or less had a good corrosion resistance in SST, and their annealed ones including $\mathrm{Zr}$ crystals also showed excellent properties because of the passivation of crystallized zirconium in the film.

\section{References}

[1] Y.-M. Sung and D.-W. Han, "Transparent conductive titanium-doped indium oxide films prepared by a magnetic null discharge sputter source," Vacuum, vol. 83, no. 1, pp. 161165,2008

[2] K. Fujiwara, H. Tanimoto, and H. Mizubayashi, "Elasticity study of very thin Cu films," Materials Science and Engineering A, vol. 442, no. 1-2, pp. 336-341, 2006.

[3] A. Ishida and M. Sato, "Ti-Ni-Cu shape-memory alloy thin film formed on polyimide substrate," Thin Solid Films, vol. 516, no. 21, pp. 7836-7839, 2008.

[4] B. Marsen, E. L. Miller, D. Paluselli, and R. E. Rocheleau, "Progress in sputtered tungsten trioxide for photoelectrode applications," International Journal of Hydrogen Energy, vol. 32, no. 15, pp. 3110-3115, 2007.

[5] V. Sittinger, A. Pflug, W. Werner, et al., "Production of MF and DC-pulse sputtered anti-reflective/anti-static optical interference coatings using a large area in-line coater," Thin Solid Films, vol. 502, no. 1-2, pp. 175-180, 2006.

[6] C. Fu, C. Yang, L. Han, and H. Chen, "The thickness uniformity of films deposited by magnetron sputtering with rotation and revolution," Surface and Coatings Technology, vol. 200, no. 12-13, pp. 3687-3689, 2006.

[7] T. Nagase and Y. Umakoshi, "Effect of electron irradiation on nano-crystallization in $\mathrm{Zr}_{66.7} \mathrm{Cu}_{33.3}$ and $\mathrm{Zr}_{65.0} \mathrm{Al}_{7.5} \mathrm{Cu}_{27.5}$ amorphous alloys," Materials Science and Engineering A, vol. 343, no. 1-2, pp. 13-21, 2003.

[8] Y. K. Kuo, K. M. Sivakumar, C. A. Su, et al., "Measurement of low-temperature transport properties of Cu-based $\mathrm{Cu}-\mathrm{Zr}$ Ti bulk metallic glass," Physical Review B, vol. 74, no. 1, Article ID 014208, 7 pages, 2006.

[9] V. Schroeder, C. J. Gilbert, and R. O. Ritchie, "Comparison of the corrosion behavior of a bulk amorphous metal, $\mathrm{Zr}_{41.2} \mathrm{Ti}_{13.8} \mathrm{Cu}_{12.5} \mathrm{Ni}_{10} \mathrm{Be}_{22.5}$, with its crystallized form," Scripta Materialia, vol. 38, no. 10, pp. 1481-1485, 1998.

[10] X. Liu, G. S. Frankel, B. Zoofan, and S. I. Rokhlin, "Insitu observation of intergranular stress corrosion cracking in AA2024-T3 under constant load conditions," Corrosion Science, vol. 49, no. 1, pp. 139-148, 2007.

[11] K. H. W. Seah, R. Thampuran, X. Chen, and S. H. Teoh, "Comparison between the corrosion behaviour of sintered and unsintered porous titanium," Corrosion Science, vol. 37, no. 9, pp. 1333-1340, 1995. 
[12] H. Huo, Y. Li, and F. Wang, "Corrosion of AZ91D magnesium alloy with a chemical conversion coating and electroless nickel layer," Corrosion Science, vol. 46, no. 6, pp. 1467-1477, 2004.

[13] V. S. Veerasamy, H. A. Luten, R. H. Petrmichl, and S. V. Thomsen, "Diamond-like amorphous carbon coatings for large areas of glass," Thin Solid Films, vol. 442, no. 1-2, pp. 1-10, 2003.

[14] P. J. Fallon, V. S. Veerasamy, C. A. Davis, et al., "Properties of filtered-ion-beam-deposited diamondlike carbon as a function of ion energy," Physical Review B, vol. 48, no. 7, pp. 47774782, 1993.

[15] Japan Industrial Standard (JIS), http://www.jsa.or.jp/default english.asp.

[16] P. R. Roberge, Corrosion Engineering: Principles and Practice, McGraw-Hill, New York, NY, USA, 2008. 

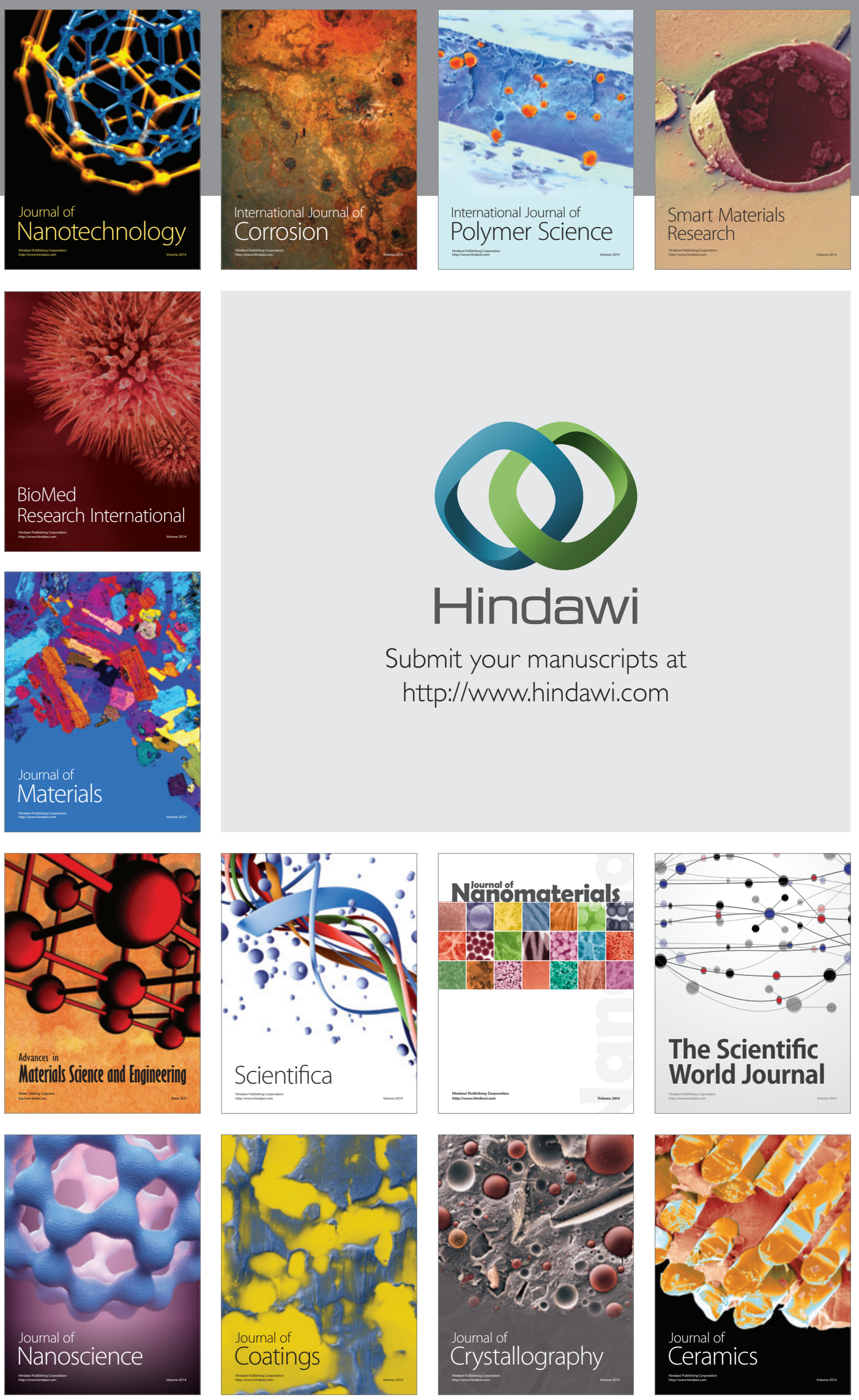

The Scientific World Journal

Submit your manuscripts at

http://www.hindawi.com

\section{World Journal}

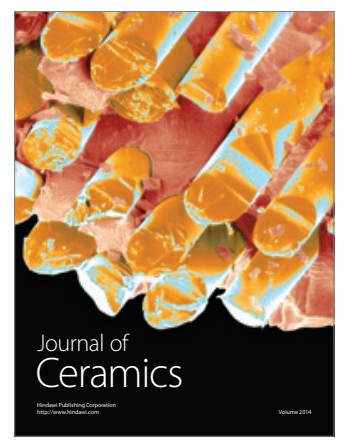

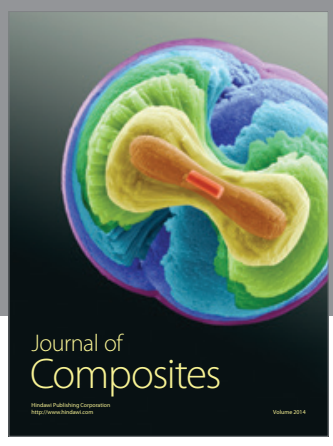
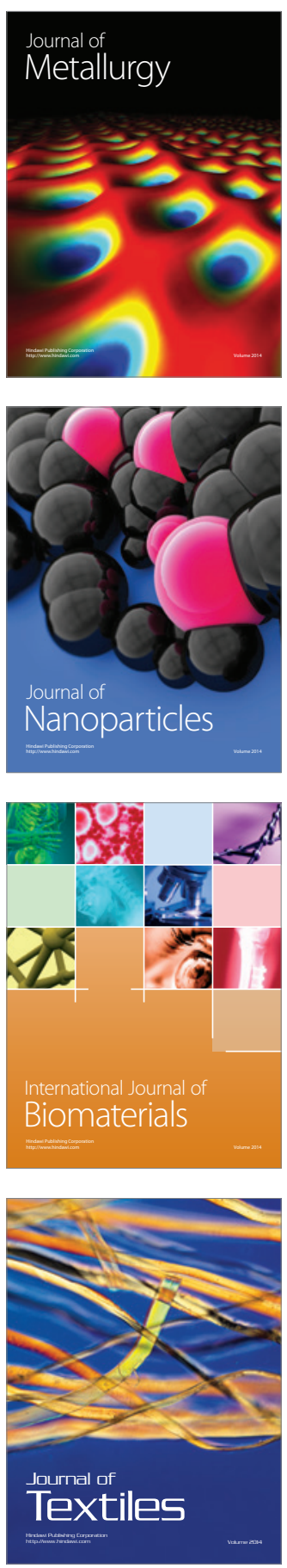